\title{
Looking at the bowl of fruit or focussing on the apples? Reply to the comments of Schueller et al.
}

\author{
Linda Bolier - Merel Haverman - Gerben J. Westerhof • Heleen Riper · Filip Smit • \\ Ernst Bohlmeijer
}

\begin{abstract}
The article of Schueller, Kashdan and Parks (2014) provides us with the opportunity to further clarify some aspects of the design and the choices we made in our meta-analysis "Positive psychology interventions: A meta-analysis of randomized controlled studies" (Bolier et al., 2013). We appreciate their commentary and endorse the useful discussion of defining positive psychological interventions for future meta-analyses. Their main concern is that we were too narrow in our inclusion strategy and should have been more inclusive by integrating effectiveness studies of related areas in positive psychology. In this reply, we argue that our strategy is equally legitimate: science is often a piecemeal effort in which the researcher limits the scope and the research question. Defining the criteria of a positive psychological intervention (PPI) can be done in a broad or a more narrow way. We acknowledge that our meta-analysis has limitations. Limitations are inherent in all meta-analyses, especially when they are published as a journal paper, which limits the scope of any work. That said, the focus of our meta-analysis was based on a conscious choice and we presented a clear description of our search strategy in order to be transparent and produce a replicable review of the literature.
\end{abstract}

\section{Scope and inclusion criteria}

The aim of our study was to make a meta-analytical overview of positive psychological interventions, that is, those interventions that were primarily aimed at increasing positive feelings, positive cognitions and positive behaviour as opposed to interventions aiming to reduce symptoms, problems or disorders. We took this definition from an earlier meta-analysis of PPIs (Sin \& Lyubomirsky, 2009). In defining inclusion criteria, we opted to include only those studies that examine interventions that have been explicitly developed in line with the theoretical focus of positive psychology. This is usually reported in the introduction section of an article. We were not so strict that the exact phrase 'positive psychology' should be used. According to our criteria, a focus on wellbeing enhancement or positive aspects of human functioning should be made explicit in the article, as opposed to a focus on problems and disease. For example, in the article of Fava, Rafanelli, Cazzaro, Conti and Grandi (1998) on the effectiveness of wellbeing therapy, 'positive psychology' is not mentioned, but they remark in the introduction: "The route of recovery lies not exclusively in alleviating the negative, but in engendering the positive" (p. 475). Therefore, this study was included (as it also met our other inclusion criteria). We agree with Schueller and colleagues (2014) that to differentiate between PPIs and other interventions, an intervention should meet both a goal criterion and a pathway criterion. By focussing on the above-mentioned criterion, both goal and pathway criteria were guaranteed in the selection of studies in our meta-analysis. 
However, not all 'pathways' were included, which was a conscious choice and was explained in the 'selection of studies' section of our meta-analysis. We tried to learn from the meta-analysis of Sin and Lyubomirsky (2009). The Sin and Lyubomirsky meta-analysis has value in its own right: it gives a first, broad, but obviously not complete, overview of the effectiveness of PPIs. They decided to include a number of studies (not all) on mindfulness and reminiscence and life review, while at the same time not including other interventions like Acceptance and Commitment Therapy or the values affirmations interventions, which Schueller et al. (2014) suggest as an intervention of choice. We decided not to include interventions that were developed from a different theoretical background, even though their commonalities with and differences from positive psychology have been spelled out in recent years (e.g. Kashdan \& Ciarrochi, 2013). Reminiscence and life review stem from psychogerontology (see Westerhof \& Bohlmeijer, 2014 for a recent review). Mindfulness stems from Buddhist traditions whereas Acceptance and Commitment Therapy is positioned as a third wave of cognitive behavioural therapy. In this way, the included interventions are much more homogeneous as they are derived from the same theoretical stream within psychology.

Another reason why we did not include interventions that use all kinds of positive psychological pathways - actually supporting the reasoning that they were developed from other traditions - is that they have been meta-analytically reviewed in their own right, as stated in our study. For example, Pinquart and Forstmeier (2012) conducted a meta-analysis of 128 studies on reminiscence and life review and showed that these interventions were not only successful in alleviating depressive symptoms, but also in enhancing positive psychological themes like wellbeing, meaning in life, and ego-integrity. It would not be conducive to furthering the field if we were to merely summarise the evidence already (superbly) summarised in Pinquart and Forstmeier's study. Similar arguments can be made for other domains that have similarities with positive psychology, such as forgiveness therapy. We thus decided to make a further delineation by excluding those areas that have already been extensively reviewed. This is not a wrong choice, as there is a conscious and grounded strategy being applied: it is just a different approach to that proposed by Schueller and colleagues (2014).

A separate issue that Schueller et al. (2014) raise is the inclusion in our meta-analysis of an old study: Lichter, Haye and Kammann (1980), while they assume that we included only studies from 1998 and further. This assumption is wrong: we searched for studies from 1998 in different databases, but being published in or after 1998 was not an inclusion criterion. The references in the meta-analysis of Sin and Lyubomirsky that were considered positive psychology interventions were also a starting point. From that meta-analysis, in which several studies from before 1998 were included, we selected only study 2 of Lichter et al. (1980) because study 1 uses an intervention that challenges irrational beliefs based on cognitive therapy, an intervention that did not fit our definition criterion.

\section{Lower pooled effect sizes}

A finding in our meta-analysis was that the overall effect size was lower than in the meta-analysis of Sin and Lyubomirsky (2009). Schueller et al. (2014) rightly stated that this may be due to our specific selection of studies. For example, the effect sizes for studies examining gratitude interventions that were included in our meta-analysis were much lower than the effect sizes for studies investigating forgiveness therapy that were included by Sin and Lyubomirsky. This could have resulted in a lower overall effect size. Schueller et al. did not mention a second important factor that might have influenced the effect size in our study. We included only studies that were randomized at the individual level. Individual randomization is one important 
criterion for the quality of a study design. This is common practice in conducting meta-analyses, but may have lowered the pooled effect size in our meta-analysis. The effects of psychotherapy for adult depression, for instance, might have been overestimated in earlier studies, because the higher quality of later studies coincided with lower effect sizes (Cuijpers, van Straten, Bohlmeijer, Hollon, \& Andersson, 2010). This finding might also apply for positive psychology and was indeed corroborated in our analysis of the moderating effects of study quality for the outcome depression. For example, the famous first happiness intervention studies (Fordyce, 1977; 1983) were excluded from our meta-analysis for this reason, as were the studies of MacLeod (2008). These studies have rather high effect sizes, but score low on methodological rigour. This methodological criterion, the inclusion of only randomized controlled trials, also partly explained why 'only' 19 studies in 17 articles (not 16 studies as Schueller et al., 2014 have stated) overlapped in the Sin and Lybomirsky meta-analysis and our meta-analysis.

Schueller and colleagues (2014) question the finding that less intensive self-help interventions were less effective than more intensive face-to-face interventions. However, it is in line with the finding of Sin and Lyubomirsky that self-administered interventions are less effective. This is, moreover, supported by reviews of online self-help interventions that are grounded in positive psychology (Bolier \& Martin Abello, 2014; Mitchell, Vella-Brodrick, \& Klein, 2010). It is questionable if this result would have been different if a more comprehensive inclusion strategy had been applied.

\section{Best possible self}

Schueller and colleagues' (2014) comments also concern the supposed incomplete status of interventions that were included in our meta-analysis. They set an example with the 'Best Possible Self' (BPS) intervention. We indeed included studies that examined the BPS intervention (Boehm, Lyubomirsky \& Sheldon, 2011; King, 2001; Layous, Nelson, \& Lyubomirsky, 2013; Lyubomirsky, Dickerhoof, Boehm, \& Sheldon, 2011; Peters, Flink, Boersma, \& Linton, 2010; Sheldon \& Lyubomirsky, 2006). Other studies were excluded or did not emerge in our search strategy (Austenfeld et al., 2006; Austenfeld \& Stanton, 2008; Hanssen, Peters, Vlaeyen, Meevissen, \& Vancleef, 2013; King \& Miner, 2000; Meevissen, Peters, \& Alberts, 2011; Oyserman, Bybee, \& Terry, 2006; Peters, Meevissen, \& Hanssen, 2013). We now look at these studies in more detail:

1) Both the Austenfeld et al. (2006) and Austenfeld and Stanton (2008) studies use only negative outcomes, such as hostility, medical visits and depression and were not aiming at enhancing wellbeing. Oyserman et al. (2006) was not focused on wellbeing, but on academic achievement. It thus comes as no surprise that these studies did not turn up in our search of databases. Besides that, Sin and Lyubomirsky (2009) have not included these three studies in their meta-analysis either, therefore they were not found when checking these references.

2) King and Miner (2000) examined a writing intervention about perceived benefits of trauma. Besides the fact that we would not consider this to be a BPS intervention, the study was excluded because of the specific goal of the intervention (post-traumatic growth).

3) Hanssen et al. (2013) and Peters et al. (2013) did not come up in our search as they were published at about the same time as our meta-analysis, but would otherwise be considered good candidates for inclusion.

4) Meevissen et al. (2011) was not found in our search strategy, even though we would have included it. If this study had been included (effect size is 0.94 , which is high), the pooled 
effect size for subjective wellbeing would not have been radically different (it rises from 0.34 to 0.35 .

It is conceivable that a meta-analysis including BPS interventions is a worthwhile undertaking, either for positive goals such as wellbeing, or for negative goals such as hostility and coping with trauma. However, this would require a different focus and correspondingly a different search strategy in comparison to our study, including the use of wider inclusion criteria.

\section{The use of depression outcomes in positive psychological interventions}

Schueller and colleagues (2014, p. 95) expressed their concern with depression as an outcome measure in intervention studies of positive psychological interventions: "the use of depressive symptoms is a bizarre attachment of intervention research in the field". They illustrate this concern with the conceptualisation by Duckworth, Steen and Seligman (2005) of the main goal of positive psychological interventions: to provide interventions that move people from average health (0) to a state of flourishing ( +3 or higher), as opposed to problem-based interventions that aim to move people from a state of suffering $(-5)$ to a normal distressed state $(-1)$. In our eyes, this is a useful conceptualisation to understand the goal of positive psychology, but it is also a very linear notion, if taken literally.

There is a growing body of evidence for a two-continua model: wellbeing and mental illness are correlated but also rather independent dimensions, and not just two opposite poles of the same continuum (Keyes, 2005; Lamers, Westerhof, Bohlmeijer, ten Klooster, \& Keyes, 2011; Weich et al., 2011). For example, people with mental complaints can experience growth in meaning in their lives. Positive psychological interventions can help people to recover (Slade, 2010). Maybe the symptoms will not fully disappear, but life perspective and meaning in life can be restored. In addition, the available evidence suggests that wellbeing increases resilience and reduces the risk of developing mental symptoms later on (Keyes, Dhingra, \& Simoes, 2010; Wood \& Joseph, 2010). As a consequence, positive psychological interventions can be used across the whole continuum of mental illness as well as that of mental health: it can be useful in diminishing psychological complaints as well as in promoting wellbeing among individuals with psychological disorders and among people in good mental health. These notions are also supported by Duckworth et al. (2005, p. 630) who mention that "positive interventions may also usefully supplement direct attempts to prevent and treat psychopathology." As seen from this perspective, it is highly relevant to measure depressive symptoms in addition to measures of wellbeing and quality of life. It is a great accomplishment that with positive psychological interventions not only is wellbeing enhanced, but depressive symptoms can be prevented and treated.

\section{Conclusion}

In sum, our meta-analysis applied a strict search and inclusion strategy, which limits the scope of the results to interventions that are explicitly grounded in positive psychology theory. This scope is in line with many other articles on positive psychology (e.g. Duckworth et al., 2005). Within the chosen approach, there is a clear message to the positive psychological research field: improve the methodological quality of effect evaluations, and work in more diverse clinical populations. We recommend that meta-analyses be conducted in the future that shed light on specific types of interventions, for example gratitude interventions and strengths-based interventions. In our view, it would also be worthwhile to review only studies using study populations in the real world as opposed to convenience samples of students in a lab setting 
(many of the studies in our meta-analysis were done in a university setting, sometimes with the incentive of course credits). The main point is that any conclusion remains conditioned on the type of interventions that were included in the meta-analysis, but choosing the focus of a metaanalysis is primarily driven by the precise research question.

Schueller and colleagues (2014) suggest an approach that is more inclusive and integrated, acknowledging a larger variety of pathways and interventions. Metaphorically speaking, they would prefer a meta-analysis of the whole bowl of fruit with apples, pears and pineapples, whereas we made a conscious decision to focus on different types of apples. We would welcome a meta-analysis based on all types of fruit, because we can see that definitions of PPIs remain in essence somewhat arbitrary and open to discussion. A more inclusive approach would perhaps allow researchers to take a meta-regression approach to identifying certain populations, modifying factors and intervention types that are particularly successful. However, we would consider this to be a very courageous proposal. We anticipate that it will be very challenging in the context of meagre research funding and in the space typically offered for papers in scientific journals. Furthermore, it raises the question where the boundary between positive psychological interventions and other type of interventions is to be set. It might be a good idea to mobilize the positive psychology research community for that reason, perhaps by opening a wiki in which definitions and selection criteria are discussed and everyone can contribute to a certain area of research. We are very willing to cooperate in such an endeavour.

\section{Authors}

Linda Bolier

Trimbos Institute

University of Twente

Merel Haverman

Trimbos Institute

Gerben J Westerhof

University of Twente

Heleen Riper

VU University

Leuphana University

Filip Smit

Trimbos Institute

VU University

Ernst Bohlmeijer

University of Twente

Publishing Timeline

Received 23 April year

Accepted 23 April year

Published 5 June year

\section{References}


Austenfeld, J. L., Paolo, A. M., \& Stanton, A. L. (2006). Effects of writing about emotions versus goals on psychological and physical health among third-year medical students. Journal of Personality, 74, 267-286. http://dx.doi.org/10.1111/j.1467-6494.2005.00375.x

Austenfeld, J. L. \& Stanton, A. L. (2008). Writing about emotions versus goals: Effects on hostility and medical care utilization moderated by emotional approach coping processes. British Journal of Health Psychology, 13, 35-38. http://dx.doi.org/10.1348/135910707X250857

Boehm, J. K., Lyubomirsky, S., \& Sheldon, K. M. (2011). A longitudinal experimental study comparing the effectiveness of happiness-enhancing strategies in Anglo Americans and Asian Americans. Cognition \& Emotion, 25, 1263-1272. http://dx.doi.org/10.1080/02699931.2010.541227

Bolier, L., Haverman, M., Westerhof, G. J., Riper, H., Smit, F., \& Bohlmeijer, E. (2013). Positive psychology interventions: A meta-analysis of randomized controlled studies. BMC Public Health, 13, 119. http://dx.doi.org/10.1186/1471-2458-13-119

Bolier, L. \& Martin Abello, K. (2013). Online Positive Psychology - State of the art and new directions. In A.C.Parks \& M. S. Schueller (Eds.), To appear in: Handbook of Positive Psychological Interventions. Oxford: Wiley-Blackwell.

Cuijpers, P., van Straten, A., Bohlmeijer, E., Hollon, S. D., \& Andersson, G. (2010). The effects of psychotherapy for adult depression are overestimated: A meta-analysis of study quality and effect size. Psychological Medicine: A Journal of Research in Psychiatry and the Allied Sciences, 40, 211223. http://dx.doi.org/10.1017/S0033291709006114

Duckworth, A. L., Steen, T. A., \& Seligman, M. E. P. (2005). Positive Psychology in clinical practice. Annual Review of Clinical Psychology, 1, 629-651. http://dx.doi.org/10.1146/annurev.clinpsy.1.102803.144154

Fava, G. A., Rafanelli, C., Cazzaro, M., Conti, S., \& Grandi, S. (1998). Well-being therapy: A novel psychotherapeutic approach for residual symptoms of affective disorders. Psychological Medicine, 28, 475-480. http://dx.doi.org/10.1017/S0033291797006363

Fordyce, M. W. (1977). Development of a program to increase personal happiness. Journal of Counseling Psychology, 24, 511-521. http://dx.doi.org/10.1037/0022-0167.24.6.511

Fordyce, M. W. (1983). A program to increase happiness: Further studies. Journal of Counseling Psychology, 30, 483-498. http://dx.doi.org/10.1037/0022-0167.30.4.483

Hanssen, M. M., Peters, M. L., Vlaeyen, J. W. S., Meevissen, Y. M. C., \& Vancleef, L. M. G. (2013). Optimism lowers pain: Evidence of the causal status and underlying mechanisms. Pain, 154, 53-58. http://dx.doi.org/10.1016/j.pain.2012.08.006

Kashdan, T. B., \& Ciarrochi, J. (2013). Mindfulness, Acceptance, and Positive Psychology: The Seven Foundations of Well-Being. Oakland: New Harbinger Publications.

Keyes, C. L. M. (2005). Mental illness and/or mental health? Investigating axioms of the Complete State Model of Health. Journal of Consulting and Clinical Psychology, 73, 539-548. http://dx.doi.org/10.1037/0022-006X.73.3.539

Keyes, C. L. M., Dhingra, S. S., \& Simoes, E. J. (2010). Change in level of positive mental health as a predictor of future risk of mental health. American Journal of Public Health, 100, 2366-2371. http://dx.doi.org/10.2105/AJPH.2010.192245

King, L. A. (2001). The health benefits of writing about life goals. Personality and Social Psychology Bulletin, 27, 798-807. http://dx.doi.org/10.1177/0146167201277003

King, L. A. \& Miner, K. N. (2000). Writing about the perceived benefits of traumatic events: Implications for physical health. Personality and Social Psychology Bulletin, 26, 220-230. http://dx.doi.org/10.1177/0146167200264008

Lamers, S. M., Westerhof, G. J., Bohlmeijer, E. T., Ten Klooster, P. M., \& Keyes, C. L. (2011). Evaluating the psychometric properties of the Mental Health Continuum-Short Form (MHC-SF). Journal of Clinical Psychology, 67, 99-110. http://dx.doi.org/10.1002/jclp.20741

Layous, K., Nelson, K. S., \& Lyubomirsky, S. (2013). What is the optimal way to deliver a positive activity intervention? The case of writing about one's best possible selves. Journal of Happiness Studies, 14, 635-654. http://dx.doi.org/10.1007/s10902-012-9346-2 
Lichter, S., Haye, K., \& Kammann, R. (1980). Increasing happiness through cognitive retraining. New Zealand Psychologist, 9.

Lyubomirsky, S., Dickerhoof, R., Boehm, J. K., \& Sheldon, K. M. (2011). Becoming happier takes both a will and a proper way: An experimental longitudinal intervention to boost well-being. Emotion, 11, 391-402. http://dx.doi.org/10.1037/a0022575

MacLeod, A. K., Coates, E., \& Hetherton, E. (2008). Increasing well-being through teaching goal-setting and planning skills: results of a brief intervention. Journal of Happiness Studies, 9, 185-196. http://dx.doi.org/10.1007/s10902-007-9057-2

Meevissen, Y. M. C., Peters, M. L., \& Alberts, H. J. E. M. (2011). Become more optimistic by imagining a best possible self: Effects of a two week intervention. Journal of Behavior Therapy and Experimental Psychiatry, 42, 371-378. http://dx.doi.org/10.1016/j.jbtep.2011.02.012

Mitchell, J., Vella-Brodrick, D., \& Klein, B. (2010). Positive psychology and the internet: A mental health opportunity. Electronic Journal of Applied Psychology, 6, 30-41.

Oyserman, D., Bybee, D., \& Terry, K. (2006). Possible selves and academic outcomes: How and when possible selves impel action. Journal of Personality and Social Psychology, 91, 188-204. http://dx.doi.org/10.1037/0022-3514.91.1.188

Peters, M. L., Flink, I. K., Boersma, K., \& Linton, S. J. (2010). Manipulating optimism: Can imagining a best possible self be used to increase positive future expectancies? The Journal of Positive Psychology, 5, 204-211. http://dx.doi.org/10.1080/17439761003790963

Peters, M. L., Meevissen, Y. M. C., \& Hanssen, M. M. (2013). Specificity of the best possible self intervention for increasing optimism: Comparison with a gratitude intervention. Terapia Psicologica, 31, 93-100. http://dx.doi.org/10.4067/S0718-48082013000100009

Pinquart, M. \& Forstmeier, S. (2012). Effects of reminiscence interventions on psychosocial outcomes: A meta-analysis. Aging \& Mental Health, 1-18.

Schueller, M. S., Kashdan, T. B., \& Parks, A. C. (2014). Synthesizing positive psychological interventions: Suggestions for conducting and interpreting meta-analyses. International Journal of Wellbeing.

Sheldon, K. M. \& Lyubomirsky, S. (2006). How to increase and sustain positive emotion: The effects of expressing gratitude and visualizing best possible selves. Journal of Positive Psychology, 1, 73-82. http://dx.doi.org/10.1080/17439760500510676

Sin, N. L. \& Lyubomirsky, S. (2009). Enhancing well-being and alleviating depressive symptoms with positive psychology interventions: A practice-friendly meta-analysis. Journal of Clinical Psychology, 65, 467-487. http://dx.doi.org/10.1002/jclp.20593

Slade, M. (2010). Mental illness and well-being: the central importance of positive psychology and recovery approaches. BMC Health Services Research, 10(26), 1-14.

Weich, S., Brugha, T., King, M., McManus, S., Bebbington, P., Jenkins, R., ... \& Stewart-Brown, S. (2011). Mental well-being and mental illness: Findings from the Adult Psychiatric Morbidity Survey for England 2007. British Journal of Psychiatry, 199, 23-28. http://dx.doi.org/10.1192/bjp.bp.111.091496

Westerhof, G. J. \& Bohlmeijer, E. (2014). Celebrating fifty years of research and applications in reminiscence and life review: State of the art and new directions. Journal of Aging studies, 29, 107114. http://dx.doi.org/10.1016/j.jaging.2014.02.003

Wood, A. M. \& Joseph, S. (2010). The absence of positive psychological (eudemonic) well-being as a risk factor for depression: A ten year cohort study. Journal of Affective Disorders, 122, 217. http://dx.doi.org/10.1016/j.jad.2009.06.032 